\title{
Straight line closure for correction of congenital isolated bilateral macrostomia
}

\author{
Narendra S. Mashalkar, Naren Shetty \\ Department of Plastic Surgery and Burns, St. John's Medical College, Koramangala, Bengaluru 560034, Karnataka, India.
}

Address for correspondence: Dr. Narendra S. Mashalkar, Department of Plastic Surgery and Burns, St. John's Medical College, Koramangala, Bengaluru 560034, Karnataka, India. E-mail: plasticnaren2005@yahoo.co.in

\begin{abstract}
Congenital bilateral macrostomia is a very rare deformity of the mouth, and it is still rarer to see cases of isolated bilateral macrostomia. Although the creation of a symmetric neocommissure is imperative, this presents a technical challenge. A review of the literature for surgical solutions revealed various techniques, but no cases in which a bilateral straight line repair was described and adopted. This report presents the case of a 3-month-old boy with isolated bilateral macrostomia for whom straight line closure was performed on both sides. At 1 year follow-up, the oral commissures are symmetric with aesthetically pleasing scars and no lateral migration.
\end{abstract}

Key words:

Bilateral macrostomia, muscle repair, straight line closure

\section{INTRODUCTION}

Transverse facial cleft is a rare congenital anomaly with only 21 cases reported in the world literature. ${ }^{[1-3]}$ Many procedures have been developed for correction of this malformation, ${ }^{[4]}$ including the vermilion square flap technique described by Eguchi et al., ${ }^{|5|}$ the Z-plasty technique described by Longacre et al. ${ }^{[6]}$ the two triangular flaps method described by Ono and Tateshita, ${ }^{[7]}$ and another correction presented by Schwarz and Sharma et al $^{[8]}$ All techniques described highlight the importance and challenge of achieving a properly positioned symmetrical neocommissure. In this report, the straight line repair of isolated bilateral congenital macrostomia is presented for the first time. The father of the child involved in this article agreed to publish the child's pictures and signed the consent form.

\section{CASE REPORT}

A 3-month-old male child presented to us for definitive correction of congenital bilateral macrostomia [Figure 1].

\begin{tabular}{|l|l|}
\hline \multicolumn{2}{|c|}{ Access this article online } \\
\hline Quick Response Code: & Website: \\
\hline & www.parjournal.net \\
\cline { 2 - 3 } & \\
\hline
\end{tabular}

The lateral extent of the cleft was located at the anterior border of the masseter muscle. After a thorough evaluation to rule out any associated anomalies, the child was scheduled for surgical correction.

Following nasal intubation, the neocommissure was determined by dropping a vertical line from the medial margin of both pupils and marking the well-defined change in color from the normal vermilion to cleft mucosa.

Both these reference points coincided [Figure 2]. The orbicularis oris was dissected and repaired after overlapping the muscle [Figures 3 and 4]. The postoperative period was uneventful [Figure 5]. At 12 months follow-up, there was no lateral migration and the aesthetic appearance was satisfactory with good oral competence [Figures 6 and 7].

\section{DISCUSSION}

The cleft of macrostomia includes a three layered defects of the skin, muscle and mucosa. ${ }^{[9]}$ Discontinuity in the muscle results in an incompetent oral sphincter. ${ }^{[9]}$ The goals of surgery for macrostomia include symmetric placement of the neocommissure, restoration of oral competence by repair of the orbicularis oris muscle, and closure of the buccal mucosa to achieve a normal contour and prevent lateral migration of the commissure. ${ }^{[9]}$ The point of the new commissure must be determined accurately to achieve the above goals. In the current 


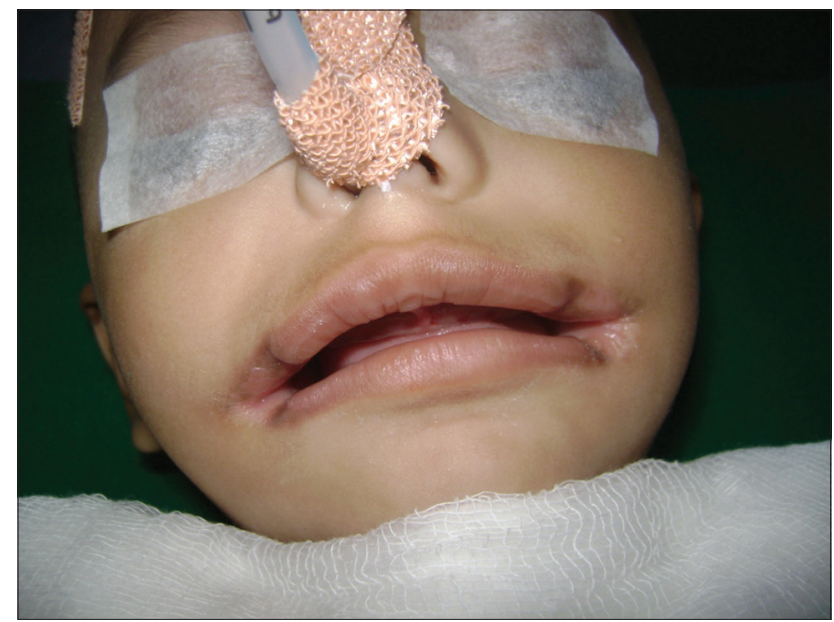

Figure 1: Preoperative view

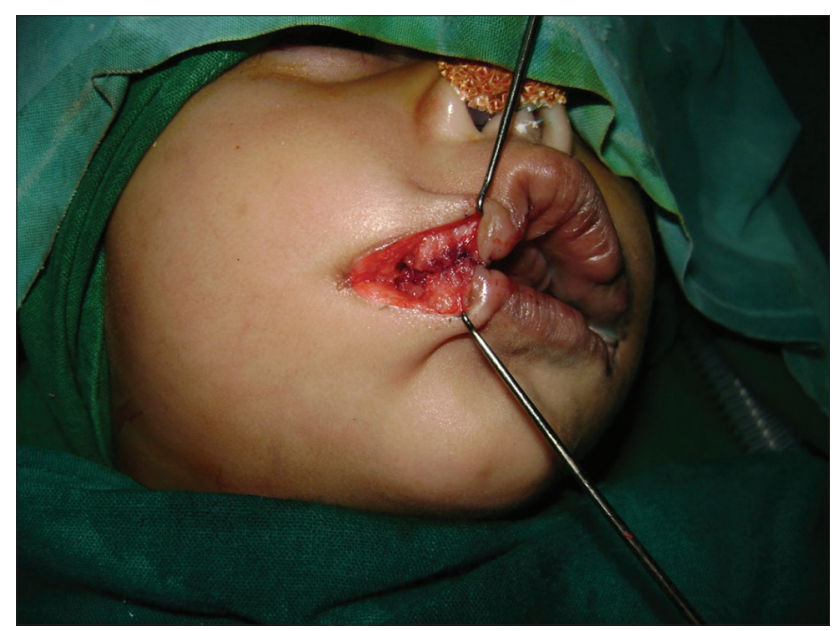

Figure 3: Muscle repair 1

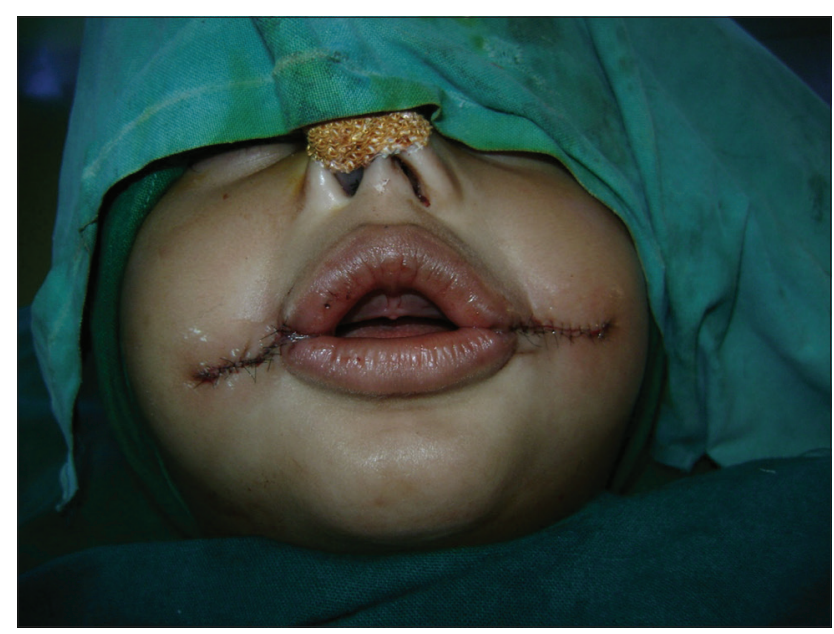

Figure 5: Immediate intraoperative photo

case, a perpendicular line was dropped from the medial margin of the pupil, and the point at which the color of vermilion changes from normal vermilion to cleft vermilion was marked. Both the points coincided, and the entire surgical correction was centered on these points. The stump of the superior orbicularis oris was closed in a double-breasted fashion to the inferior orbicularis stump under adequate tension with reference to the overlying commissure. This maneuver is of vital

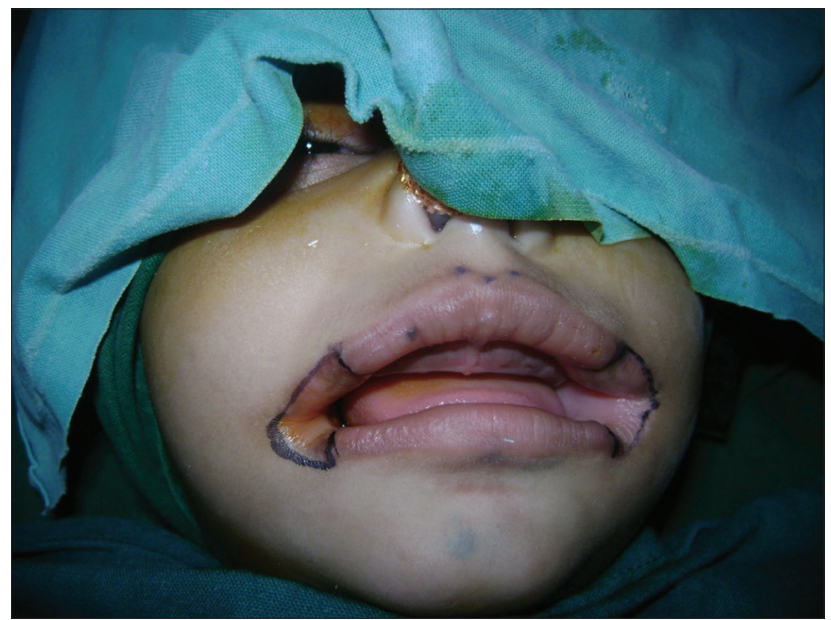

Figure 2: Markings intraoperative

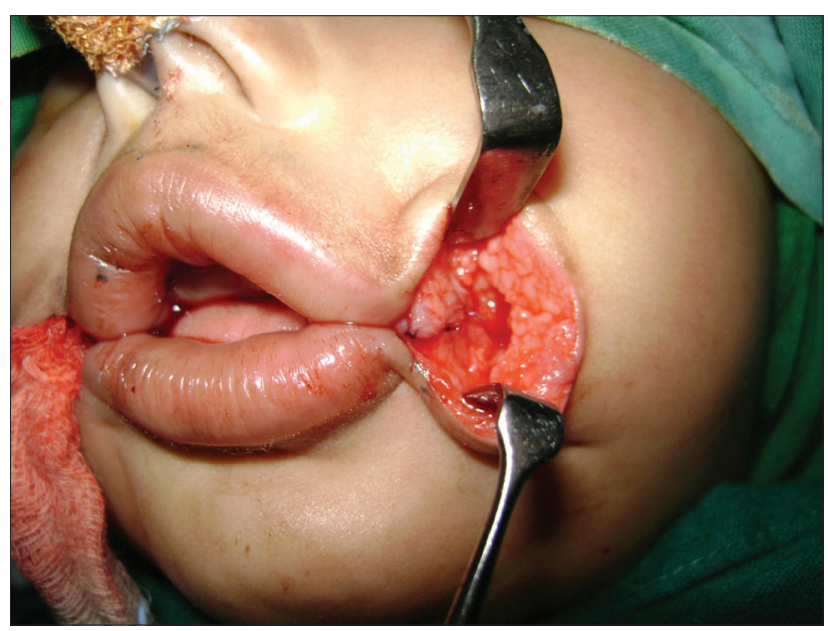

Figure 4: Muscle repair 2

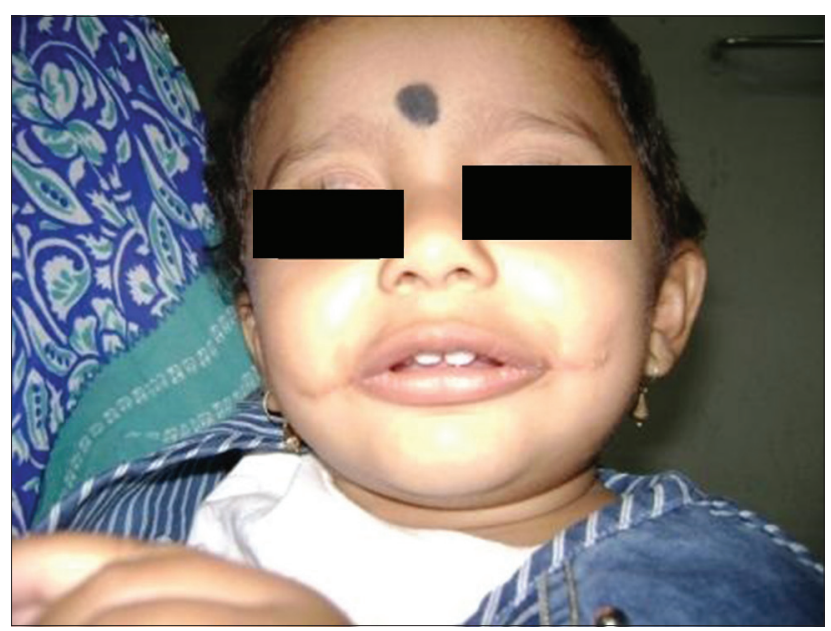

Figure 6: Postoperative 6 months

importance in creating competence, shape and contour at the commissure. ${ }^{[9]}$

Vermilion square flap commissuroplasty is another technique, which has previously shown good results. ${ }^{[8]}$ The Z-plasty technique has fallen out of favor as the scar is more visible, particularly when smiling. ${ }^{[3]}$ Yoshimura et al. $^{[10]}$ performed a study in which he compared five children with a Z-plasty repair and seven with a simple 


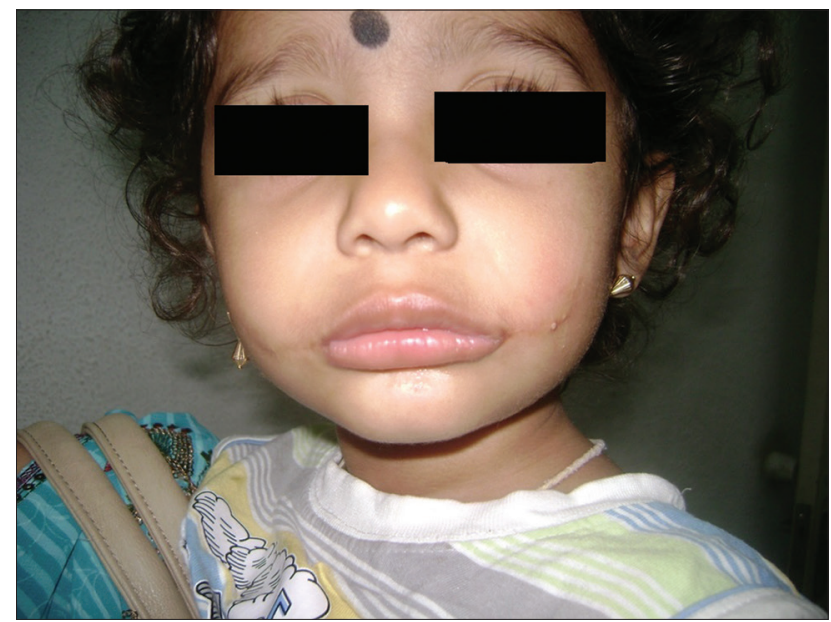

Figure 7: Postoperative 1 year follow-up

line repair, and found that Z-plasty gives a less aesthetic result. Schwarz made a similar observation with regard to the Z-plasty repair. ${ }^{[10]}$ Younger patients are also at high risk of lateral migration of the commissure with advancing age with this technique. ${ }^{[4]}$

In conclusion, simple line closure is a technically simple procedure and provides an esthetically pleasing scar without lateral migration or contraction in patients operated on at a young age.

\section{REFERENCES}

I. Makhija LK, Jha MK, Bhattacharya S, Rai A, Dey AB, Saha A. Transverse facial cleft: a series of 17 cases. Indian J Plast Surg 201 1;44:439-43.

2. Gleizal A, Wan DC, Picard A, Lavis JF, Vazquez MP, Beziat JL. Bilateral macrostomia as an isolated pathology. Cleft Palate Craniofac J 2007;44:58-6I.

3. Mahtar M, Benjelloun A, Chekkoury Idrissi A. Bilateral congenital macrostomia. Rev Stomatol Chir Maxillofac 2007; 108:55-7.

4. Torkut A, Coskunfirat OK. Double reversing Z-plasty for correction of transverse facial cleft. Plast Reconstr Surg 1997;99:885-7.

5. Eguchi T, Asato PH, Takushima A, Takato T, Harii PK. Surgical repair for congenital macrostomia: vermilion square flap method. Ann Plast Surg 200I;47:629-35.

6. Longacre Jj, deStefano GA, Hommstrand KE. The surgical management of first and second brachial arch syndromes. Plast Reconstr Surg 1963;3 I:507-20.

7. Ono I, Tateshita T. New surgical technique for macrostomia repair with two triangular flaps. Plast Reconstr Surg 2000; 105:688-94.

8. Schwarz R, Sharma D. Straight line closure of congenital macrostomia. Indian J Plast Surg 2004;37:121-3.

9. Chang $\mathrm{HH}$, Tang YB, Hsu WM, Chen MT, Hsieh MH. Vermilion square flap for correction of bilateral macrostomia - A case report. J Plast Surg Assoc ROC 2008; 1 7:399-404.

10. Yoshimura Y, Nakajima T, Nakanishi Y. Simple line closure for macrostomia repair. Br J Plast Surg 1992;45:604-5.

How to cite this article: Mashalkar NS, Shetty N. Straight line closure for correction of congenital isolated bilateral macrostomia. Plast Aesthet Res 2015;2:95-7.

Source of Support: Nil, Conflict of Interest: None declared.

Received: 23-07-2014; Accepted: 17-12-2014 